Linköping Studies in Science and Technology.

Thesis No. 1645

\title{
Modelling of fatigue crack propagation in Inconel 718 under hold time conditions
}

\author{
Erik Lundström
}

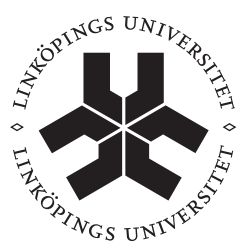

\section{Linköping University}

INSTITUTE OF TECHNOLOGY

Division of Solid Mechanics

Department of Management and Engineering

Linköping University, SE-581 83, Linköping, Sweden

Linköping, February 2014 
Cover:

Kb-specimen with indicated crack length and damaged zone. The test specimen is subjected to a flight spectrum which is accurately predicted by letting the crack growth rate be dependent on the damaged zone $D$, which is built up during hold times and consumed during load reversals.

Printed by:

LiU-Tryck, Linköping, Sweden, 2014

ISBN: 978-91-7519-403-5

ISSN: 0280-7971

Distributed by:

Linköping University

Department of Management and Engineering

SE-581 83, Linköping, Sweden

\section{(c) 2014 Erik Lundström}

This document was prepared with $\mathrm{AT}_{\mathrm{E} X}$, February 16, 2014

No part of this publication may be reproduced, stored in a retrieval system, or be transmitted, in any form or by any means, electronic, mechanical, photocopying, recording, or otherwise, without prior permission of the author. 


\section{Preface}

The work presented in this thesis has been carried out at the Division of Solid Mechanics, Linköping University within the project High temperature fatigue crack propagation in nickel-based superalloys, which is a part of the research programme TURBO POWER. The programme is a joint collaboration between the Swedish Energy Agency, Siemens Industrial Turbomachinery AB and GKN Aerospace Engine Systems, from which support and founding are gratefully acknowledged.

I would like to thank my supervisor Prof. Kjell Simonsson for all his support and guidance. I would also like to thank my assistant supervisors Dr. Tomas Månsson, GKN Aerospace Engine Systems, Dr. David Gustafsson, Siemens Industrial Turbomachinery AB and Dr. Johan Moverare, Linköping University. I would also like to give a very special thanks to Prof. Sören Sjöström, Linköping University for all valuable discussions and support during my work on this thesis. My colleagues at the Division of Solid Mechanics are also gratefully acknowledged for all their help. I would also like to thank the project teams at Linköping University, Siemens Industrial Turbomachinery AB and GKN Aerospace Engine Systems for valuable discussions, a special thanks to Dr. Thomas Hansson (GKN) for his support with the mechanical testing and evaluation, Lic. Eng. Per Almroth (SIT), Lic. Eng. Björn Sjödin (SIT), Prof. Sten Johansson, Linköping University, and Dr. Magnus Hörnqvist (GKN) for valuable discussions.

Finally, I would like to thank my family and friends for all their support.

Erik Lundström

Linköping, February 2014 



\section{Abstract}

In this thesis an investigation and modelling of the fatigue crack propagation in the nickel based superalloy Inconel 718, with a special emphasis on the effect of hold times, is presented. The modelling work has been concentrated on describing the hold time fatigue crack propagation by using the concept of a damaged zone in front of the crack tip, which is believed to have a lowered resistance against crack propagation.

The modelling framework is built on physically motivated parameters, which are all easy to calibrate through one specially designed test type. Later evaluation through many experimental tests has also shown that the model is capable, within reasonable scatter level to predict, the hold time fatigue crack propagation for many different temperatures and loading conditions. Further evaluation of a complex flight spectrum, with the incorporation of crack closure within the model, was also predicted with a satisfying result.

This thesis is divided into two parts. First, a background and a somewhat deeper discussion of the modelling of fatigue crack growth under hold time conditions is presented. The second part consists of five appended papers, which describe the work completed so far in the project. 



\section{List of Papers}

In this thesis, the following papers have been included:

I. D. Gustafsson, E. Lundström (2013). High temperature fatigue crack growth behaviour of Inconel 718 under hold time and overload conditions, International Journal of Fatigue, Volume 48, pp. 178-186.

II. D. Gustafsson, E. Lundström, K. Simonsson (2013). Modelling of high temperature fatigue crack growth in Inconel 718 under hold time conditions, International Journal of Fatigue, Volume 52, pp. 124-130.

III. E. Lundström, K. Simonsson, D. Gustafsson, T. Månsson (2014). A load history dependent model for fatigue crack propagation in Inconel 718 under hold time conditions, accepted for publication in Engineering Fracture Mechanics.

IV. E. Lundström, K. Simonsson, T. Månsson, D. Gustafsson (2014). Modelling of fatigue crack growth in Inconel 718 under hold time conditions - application to a flight spectrum, Advanced Materials Research, Volumes. 891-892, pp. 759-764.

V. E. Lundström, K. Simonsson (2014). Evaluation and prediction of crack length in a Ni-based superalloy for sustained loading, submitted.

Own contribution

In the first two papers work has been shared with the co-authors. In the last three papers I have done the writing, modelling work and part of the microscopy work. Testing has been done by Mr. Bo Skoog, Mr. Patrik Härnman, Linköping University, and myself, except for paper IV where part of the testing was performed at GKN Aerospace in Trollhättan, all subsequent evaluation has been done by me. SEM work has been supported by Prof. Sten Johansson, Dr. Robert Eriksson and Lic. Eng. Mattias Calmunger at the Div. of Engineering Materials, Linköping University. 



\section{Contents}

Preface $\quad$ iii

Abstract $\quad$ v

List of Papers vii

Contents ix

Part I - Background 1

1 Introduction 3

1.1 Background ......................... . . 3

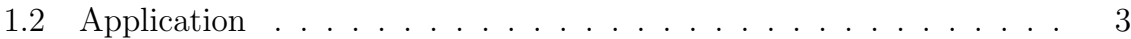

1.2 .1 Industrial usage . . . . . . . . . . . . . . . . . . . . 4

1.3 Aim of this work . . . . . . . . . . . . . . . . . 5

1.4 Outline . . . . . . . . . . . . . . . . . 6

$\begin{array}{lll}2 & \text { Superalloys } & 7\end{array}$

2.1 Composition . . . . . . . . . . . . . . . . . . 7

2.1 .1 Inconel $718 \ldots \ldots . \ldots . \ldots . \ldots . \ldots . \ldots 8$

3 Fatigue crack propagation $\quad 9$

3.1 Paris law . . . . . . . . . . . . . . . . . . . . . . . . 9 9

3.2 Fatigue crack closure . . . . . . . . . . . . . . . . . . 10

3.2 .1 Calibration .................... . . 11

3.3 Further modifications . . . . . . . . . . . . . . . . . . . 12

3.4 Summary . . . . . . . . . . . . . . . . . . . . . 12

4 Hold time fatigue crack growth $\quad \mathbf{1 5}$

4.1 Hold time effects . . . . . . . . . . . . . . . . . . . . . 15

4.2 Hold time models . . . . . . . . . . . . . . . . . . . . . . 17

4.2.1 Examples of different models . . . . . . . . . . . . . . . . . 17

5 Test programme 23 
6 Modelling work 25

6.1 Damage mechanisms . . . . . . . . . . . . . . . . . 25

6.2 Observation of unbroken ligaments - damaged zone . . . . . . . . . 26

6.3 The basis of the model . . . . . . . . . . . . . . . . . 31

6.3.1 Damaged zone build-up . . . . . . . . . . . . . . 32

6.3.2 Damaged zone consumption . . . . . . . . . . . . . . 34

6.4 Crack propagation law . . . . . . . . . . . . . . . . . . . . 34

6.4.1 Results ....................... 35

$\begin{array}{lll}7 & \text { Future work } & 39\end{array}$

8 Review of included papers 41

Part II - Included papers $\quad 49$

Paper I: High temperature fatigue crack growth behaviour of Inconel 718 under hold time and overload conditions . . . . . . . . . . . 53

Paper II: Modelling of high temperature fatigue crack growth in Inconel 718 under hold time conditions . . . . . . . . . . . . . 65

Paper III: A load history dependent model for fatigue crack propagation in Inconel 718 under hold time conditions . . . . . . . . . . . . . . . 75

Paper IV: Modelling of fatigue crack growth in Inconel 718 under hold time conditions - application to a flight spectrum . . . . . . . . . . 99

Paper V: Evaluation of crack length under hold time conditions in Inconel 718 using a damaged zone concept . . . . . . . . . . . . 107 


\title{
Part I
}

\author{
Background
}





\section{Introduction}

\subsection{Background}

Fatigue crack propagation is one of the most challenging problems to deal with. However, although much research has been made in the area, there are still many challenging problems which remain to be solved. New applications and/or new environmental conditions for existing and future components are examples of situations where already developed models might have difficulties to meet an acceptable life expectancy.

Already existing models for fatigue crack propagation are, when needed, modified to handle different load ratios, threshold values, or other conditions which may apply, e.g. environmental effects, which is always a necessity for accurate life prediction. Even so, the life of components is still in many cases, very hard to foresee accurately, as many different parameters can be of influence. As a result, many components used today are designed with a large margin regarding final life, which with better life prediction methods could be avoided. One of the areas which has not yet been paid sufficient attention to is the load case of high temperatures of sustained, or slowly applied loads, in this work referred to as hold time.

\subsection{Application}

A gas turbine interior, see Fig. 1, is one of the most extreme and hostile environments a material can be subjected to, with metal temperatures ranging all the way up to $1000{ }^{\circ} \mathrm{C}$ in the hottest blade sections [1]. Since the first development of gas turbines, the goal has always been to strive for higher efficiency, which means elevating the turbine temperature. Further, future aero engines and stationary gas turbines will probably not be subjected to the same type of loading or environmental conditions as we are used to see them operate in today. Future engines must be able to handle, e.g., different types of fuels, as bio-fuels, or different load cycles, as the need for power output changes with the introduction of alternative power sources, as e.g. wind and solar power are not reliable to deliver constant power output at all times. Consequently, reliable crack propagation models is one of the 
most important issues to handle as materials needed for coping with these extreme conditions are often pushed to their limits.

One such loading condition which can be intensively seen today is hold times. These can e.g. be seen under cruise in aero engines, in land based turbines at continuous power output, at slow ramp up of engine thrust, or at low frequency loading of stationary turbines for irregular power output. The influence of these hold times is seen to have a major impact on the crack propagation rate, and it has been shown that material damage at the crack tip causes the crack to grow by intergranular fracture and thus strongly increases the crack growth rate. Here the nickel-based superalloy Inconel 718 has been considered, which is one of the most commonly found alloys in the modern gas turbine industry.

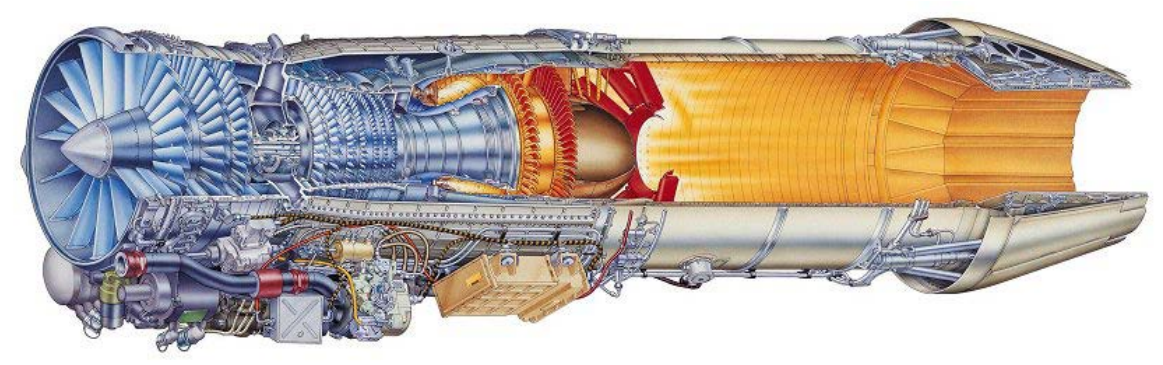

Figure 1: RM12 aero engine. Courtesy of GKN Aerospace Engine Systems.

The issues discussed above are likely have a major impact on the future gas turbine market and, as a result of this, the Swedish research programme TURBO POWER was initiated, within which the work in this thesis has been carried out. The programme is a joint collaboration between the Swedish Energy Agency, Siemens Industrial Turbomachinery AB, GKN Aerospace Engine Systems and several Swedish universities, whose objectives are to contribute to a sustainable and efficient global energy system in medium term and long term view by, see [2]

- reaching higher energy usage (efficiency improvements)

- lower emissions

- better operation economy

- fuel flexibility, in particular regarding renewable fuels.

\subsubsection{Industrial usage}

The most important part of the project of developing models for the fatigue crack propagation behaviour under hold time is the usage on industrial problems seen today and in future markets. For application in gas turbines today one has to consider the analysis complete life which mainly consists of two parts 
1. life to crack initiation

2. life by crack propagation

The two processes need to be handled together for the complete life expectancy to be accurate. Many components manufactured today have defects or stress concentrations at notches which can, by long or short term use, initiate a crack, which eventually may propagate to failure. The choice of manufacturing method does affect the life, however. Even if a good manufacturing process has been chosen, the material can always show defects. Good materials which normally give long life, can by defects lead to designs with strongly reduced life.

One such example is welds, where the scatter in life is substantial. This will of course generate a very complex problem, where every modelling parameter becomes important. Large errors will be introduced if e.g. a correct life prediction model of the material behaviour is absent, which in turn will affect the economical aspect of the situation.

A complete life assessment tool will have to consider all the aspect mentioned, i.e.

- manufacturing

- inspection, e.g. x-ray

- modelling, both initiation and propagation

It therefore becomes apparent that accurate life prediction models are necessary, both when considering safety and cost of relevant components.

\subsection{Aim of this work}

The work carried out in this thesis is made within the TURBO POWER project High temperature fatigue crack propagation in nickel-based superalloys, and focuses on the development of crack propagation models for high temperature hold times, which has shown to have a devastating effect on the crack propagation behaviour. The project is focused on the nickel-based superalloy Inconel 718, here in wrought form, which is a commonly used alloy in the turbine industry, e.g. as turbine disc material. Part of the problem is therefore to understand how the considered material responds to different types of loading situations, before the work with constructing adequate models begins. During the process of developing models, a central issue has always been that the outcome of the work should be applicable in the gas turbine industry, and therefore some criteria have been set up for the models. More precisely they should

- be simple enough to be used on a daily basis

- allow for simple and cheap model parameter estimation 
- contribute to more accurate life predictions in order to fulfill the goals set by the TURBO POWER programme.

\subsection{Outline}

The first part of this thesis introduces the reader to the subjects of nickel-based superalloys and fatigue crack propagation, with a special emphasis on the effect of hold times. The second part consists of five appended papers, which report the work completed so far in the project. 


\section{Superalloys}

Designed to run under extreme heat, high stresses, oxidation and corrosive environments, often close to the melting temperature, superalloys have become a dominating alloy category within the gas turbine industry. In superalloys, one generally uses $\mathrm{Ni}$, Co or Ni-Fe as base materials $[1,3,4]$. Although all three types are found, it is mainly the $\mathrm{Ni}$ - or $\mathrm{Ni}-\mathrm{Fe}$ base alloys which have lately risen to be the primary choice among turbomachienery developers, since they have good properties and are relatively cheap [1]. It may be noted that over $50 \%$ of an aero engine's weight comes from these alloy combinations [4]. Cost is also the factor of choice between pure $\mathrm{Ni}$ and $\mathrm{Ni}-\mathrm{Fe}$ materials, Fe is cheaper than Ni, however, note that $\mathrm{Fe}$ has some negative influences e.g. lowering of the oxidation resistance [1]. In this project, focus has been on the Ni-Fe based alloy Inconel 718, which is commonly seen in e.g. turbine discs.

\subsection{Composition}

As the fifth most common element on earth, Ni is ductile and tough and gives good creep resistance [5], which is important, especially in high temperature environments. Often consisting of more than 10 different alloying elements, a superalloy is a very complex alloy, which in addition consist of many different phases. The main phase which all superalloys consists of is the matrix phase ( $\gamma$-phase); mainly consisting of $\mathrm{Ni}$, but also various other elements for solid solution strengthening, among them, e.g. Co, Cr, Mo, Fe, W [4, 5].

A $\gamma^{\prime}$ phase $\left(\mathrm{Ni}_{3} \mathrm{Al}, \mathrm{Ti}\right)$ plays the role as principal strengthening phase in many $\mathrm{Ni}$ or Ni-Fe superalloys. By adjusting the alloy content of e.g. Ta, $\mathrm{Nb}$ and $\mathrm{Cr}$, the $\gamma^{\prime}$ phase can be altered to increase or decrease [1].

In many $\mathrm{Ni}-\mathrm{Fe}$ alloys $\mathrm{Nb}$ is also used, forming $\mathrm{Ni}_{3} \mathrm{Nb}, \gamma^{\prime \prime}$. This phase is in Ni-Fe superalloys seen as the main strengthening phase instead of $\gamma^{\prime}$, as in pure Ni base alloys.

However, $\gamma^{\prime \prime}$ is a metastable phase, and long exposure times above $650{ }^{\circ} \mathrm{C}$, or the absence of $\mathrm{Fe}$ [4], leads to the formation of the stable $\delta$ phase instead, but with the same composition as $\gamma^{\prime \prime}$. This phase does not add strength, which means that heat treatment has to be carefully monitored [4]. In addition to the phases mentioned 
above, $\mathrm{C}$ and $\mathrm{B}$ are added, which form various types of carbides and borides and function as $\gamma$ grain boundary strengtheners. For a more comprehensive discussion of the different phases, elements used for superalloy compositions, and superalloys in general, see $[1,3-5]$.

\subsubsection{Inconel 718}

The superalloy used in this project is the Ni-Fe based alloy Inconel 718 in wrought form, which is a frequently used alloy, representing almost half of the total tonnage of superalloys used worldwide [1], which for obvious reasons makes it an important alloy to investigate and to understand to its fullest. The alloy has all the important properties of a Ni-Fe base alloy, as described above, and its composition is shown in Table 1.

Table 1: Composition of Inconel 718 [1].

\begin{tabular}{llllllllll}
\hline Element & $\mathrm{Ni}$ & $\mathrm{Fe}$ & $\mathrm{Cr}$ & $\mathrm{Mo}$ & $\mathrm{Al}$ & $\mathrm{Ti}$ & $\mathrm{Nb}$ & $\mathrm{C}$ & $\mathrm{B}$ \\
\hline $\mathrm{wt} \%$ & 52.5 & 18.5 & 19.0 & 3.0 & 0.5 & 0.9 & 5.1 & 0.04 & 0.02 \\
\hline
\end{tabular}




\section{Fatigue crack propagation}

A component life can vary heavily depending on the loading it is subjected to. Unlike the resistance of a component to withstand static failure, in most cases the fatigue crack propagation life depends on cyclic loading (if not considering environmental damage). Accurate life prediction models are therefore of utmost importance, and as will be discussed later, not only cyclic loading will be of major influence, e.g. hold time can have a substantial effect on the life of a component, especially if subjected to elevated temperature, e.g. in gas turbine components.

Fatigue crack propagation is in most materials assumed to be a basically linear elastic process due to the very small plastic zone at the crack tip, for loadings well below the yield limit. The linear elastic fracture mechanics (LEFM) theory has been the dominating one due to its relatively simplicity in creating acceptable accurate life predictions for most materials. Some exceptions are seen for very ductile materials with larger plastic zones, where other theories might apply (not discussed here). The LEFM theory is built on the stress intensity factor $K$ which has proven its validity for many cases from its earliest development in the 1960s, as it to this very day is used for predicting life in many engineering problems. The stress intensity factor can be defined for three different load modes, namely tensile loading (I), in-plane shear (II), and out-of-plane shear (III), where the first (I) is considered to be the most important one and will completely define life for most materials. Consequently, only $K_{I}$ will from now on be considered. Below, the basic treatment for cyclic fatigue crack propagation problems is given, with the main emphasis on the most commonly seen engineering solutions for various problems.

\subsection{Paris law}

Of all fatigue crack propagation models developed, the dominating one today is still Paris law [6, 7], see Eq. (1) below, where the influence of the stress intensity 
stress intensity range $\Delta K$ on the crack growth rate is given by a power law.

$$
\begin{aligned}
\frac{\mathrm{d} a}{\mathrm{~d} N} & =C \Delta K^{n} \\
\Delta K & =K_{\max }-K_{\min } \\
K_{I} & =\sigma \sqrt{a \pi} \times g
\end{aligned}
$$

where $g$ is a geometrical factor depending on crack shape and type of loading.

Some modifications have been added by various authors to handle different situations in order to give more accurate life predictions, see the different sections below.

\subsection{Fatigue crack closure}

Perhaps the most important modification of Paris law is the introduction and description of (plastically induced) crack closure, which has become the most common way to take care of different load ratios $\left(R_{\sigma}=\sigma_{\min } / \sigma_{\max }\right)$. From its discovery in the 1970s [8] and onwards, it has been argued that the crack opens at a higher value than $K_{\min }$, due to compressive residual stresses in the plastic wake behind the crack tip [9]. The crack faces come into premature contact, so instead of $\Delta K=K_{\max }-K_{\min }$ this gives the effective stress intensity factor $\Delta K_{\text {eff. }}=K_{\max }-K_{\text {open }}$, i.e. part of the loading cycle does not contribute to crack advancement. Many models have since then been developed, such as the one by Newman [10] among others, see Table 2 which is based on stabilised values for constant amplitude loading.

Table 2: Crack closure by Newman $[9,10]$.

$$
\begin{aligned}
& \frac{\mathrm{d} a}{\mathrm{~d} N}=C\left[\frac{1-f}{1-R} \Delta K\right]^{n} \\
& f=\frac{K_{\mathrm{op}}}{K_{\max }}=\left\{\begin{array}{cc}
\max \left(R, A_{0}+A_{1} R+A_{2} R^{2}+A_{3} R^{3}\right) & R \geq 0 \\
A_{0}+A_{1} R & -2 \leq R<0
\end{array}\right. \\
& A_{0}=\left(0.825-0.34 \alpha+0.05 \alpha^{2}\right)\left[\cos \left(\pi \sigma_{\max } / 2 \sigma_{0}\right)\right]^{1 / \alpha} \\
& A_{1}=(0.415-0.071 \alpha) \sigma_{\max } / \sigma_{0} \\
& A_{2}=1-A_{0}-A_{1}-A_{3} \\
& A_{3}=2 A_{0}+A_{1}-1
\end{aligned}
$$

In the above table, $\alpha$ is a constraint parameter, $\alpha=1$ for plane stress and $\alpha=3$ for plane strain, while $\sigma_{\max } / \sigma_{0}$ is the ratio of the max stress to the flow stress 
$\left(\left(\sigma_{\mathrm{Y}}+\sigma_{\mathrm{UTS}}\right) / 2\right)$. Even though specified, both $\alpha$ and $\sigma_{\max } / \sigma_{0}$ may be used as fitting parameters in the applications discussed here [9]. In Table 2 the function $f$ shows at what ratio of $K_{\max }$ the crack will open, consequently, $f \geq 0$. By varying the two parameters, $\alpha$ and $\sigma_{\max } / \sigma_{0}$, different closure levels will be obtained, examples of this are seen in Fig. 2.

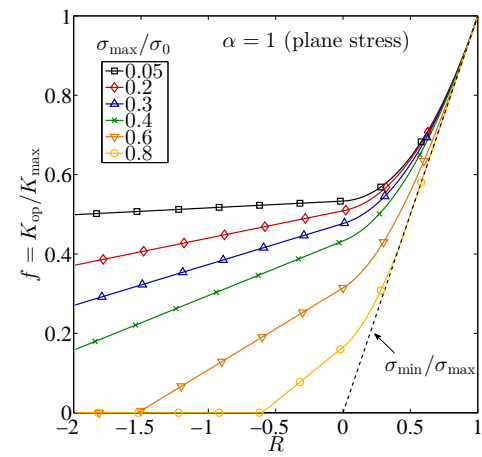

(a)

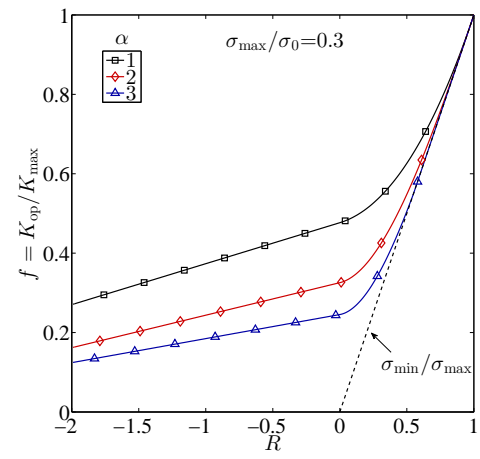

(b)

Figure 2: Closure levels for various sets of parameters, $\sigma_{\min } / \sigma_{\max }$ indicates no closure effect. (a) Varying $\sigma_{\max } / \sigma_{0}$ and (b) varying $\alpha$.

It may be noted that the above equation for the closure level in Table 2 can be rewritten as

$$
\begin{aligned}
\frac{\mathrm{d} a}{\mathrm{~d} N} & =C\left[\frac{1-f}{1-R} \Delta K\right]^{n} \\
& =C\left[\frac{K_{\max }-K_{\mathrm{op}}}{K_{\max }\left(1-\frac{K_{\min }}{K_{\max }}\right)}\left(K_{\max }-K_{\min }\right)\right]^{n} \\
& =C\left[\Delta K_{\mathrm{eff} .}\right]^{n}=C\left[K_{\max }-K_{\mathrm{op}}\right]^{n}
\end{aligned}
$$

and that the expression may be complemented to also describe the primary and tertiary phases of the fatigue crack propagation process (see below).

\subsubsection{Calibration}

The above concept can then be used to obtain an equivalent $C$ parameter (cf. Paris law), which can be applied to all $R$-ratios. The specific closure levels are then obtained depending on what loading one cycle experiences. Examples of usage is the application to e.g. predict constant amplitude loading [11], or spectrum loading [12], where the calibration procedure for the latter case is seen in Fig. 3. 
The parameters used for calibration was $\alpha=2.5$, which represents almost plane strain, and $\sigma_{\max } / \sigma_{0}=0.3$, which seems to work for most materials [9].



(a)

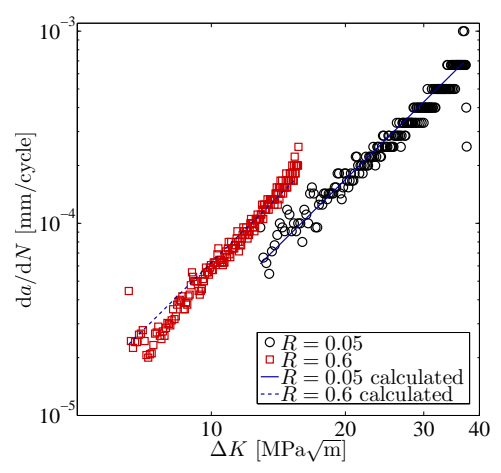

(b)

Figure 3: Calibration of crack closure for two tests at different load ratios. (a)

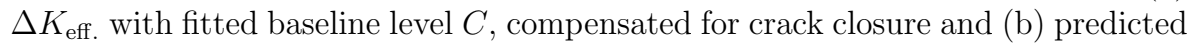
closure level for two load ratios.

\subsection{Further modifications}

More add-ons for handling the behaviour at both the lower threshold value where crack growth exists, i.e. $K_{\mathrm{th}}$, and the upper critical value where the component breaks, $K_{c}$, are typically introduced in the NASGRO equation [9], see Eq. (3).

$$
\frac{\mathrm{d} a}{\mathrm{~d} N}=C\left[\frac{1-f}{1-R} \Delta K\right]^{n} \frac{\left(1-\frac{\Delta K_{\mathrm{th}}}{\Delta K}\right)^{p}}{\left(1-\frac{K_{\max }}{K_{\mathrm{c}}}\right)^{q}}
$$

\subsection{Summary}

The whole concept of the crack propagation is presented in in Fig. 4, where the typically observed regions of the fatigue crack propagation for metals are seen, note the linear region in the middle, commonly known as the Paris-region. Even though some of the more important crack propagation laws for cyclic loading have been presented above, the field of fracture mechanics is huge, and the reader is referred to, e.g., [9] for a more comprehensive discussion of other influencing factors, e.g. overloads. In later years the attention has been placed on predicting fatigue crack 
growth in arbitrary structures, which is typically handled by contour integrals, e.g. the $J$ integral or variants of its formulation. However, this topic will not be discussed here.

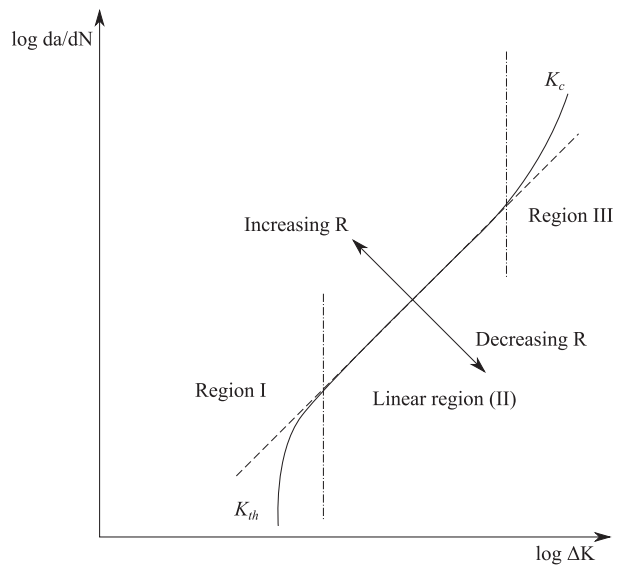

Figure 4: Fatigue crack propagation curve with the different regions commonly seen for most metallic materials.

With the above equations, the majority of the engineering fatigue crack propagation problems can be handled with reasonable accuracy. More complex models could be applied, but one must also consider the scatter between different batches etc. which may have a great influence on the number of cycles to failure. 



\section{Hold time fatigue crack growth}

A majority of the fatigue crack propagation problems seen today concern pure cyclic loading. However, there is a significant portion that is not. For many gas turbine applications, high temperature hold time loading can be seen during many different parts of the load cycle. As discussed in Chapter 1, hold times can be seen as slowly applied loads and sustained loadings, which can for some materials not only give rise to a time dependent crack growth but also impose a completely different crack growth behaviour. The lack of reliable models in this area is the main objective behind this research, as a model which is able to predict this behaviour will be of great interest for industry as well as for academic purposes. The outline of the coming sections will therefore concern the the effect and development of fatigue crack propagation models under hold time conditions.

\subsection{Hold time effects}

Hold times can increase the crack propagation rate substantially, see Fig. 5, where the hold time fatigue crack growth rate for $550{ }^{\circ} \mathrm{C}$ is shown for various sustained load cycles in Inconel 718. The effect is seen for a number of different materials in many high temperature applications, e.g. Inconel 718 [13-17], low-alloy steel [18], Inconel 100 [19], and Inconel 718, 706, 783, Udimet 720 and Waspaloy [20]; all for various temperatures (although mainly for $650{ }^{\circ} \mathrm{C}$ ) and lengths of the hold times. Further, in e.g. [21, 22] a characterization of how loading frequencies influence the hold time behaviour of Inconel 718 was made, e.g. a sine wave of of low frequency, and it was shown that not only sustained loading gave hold time effects, which further emphasises the importance of being able to predict the phenomenon. 


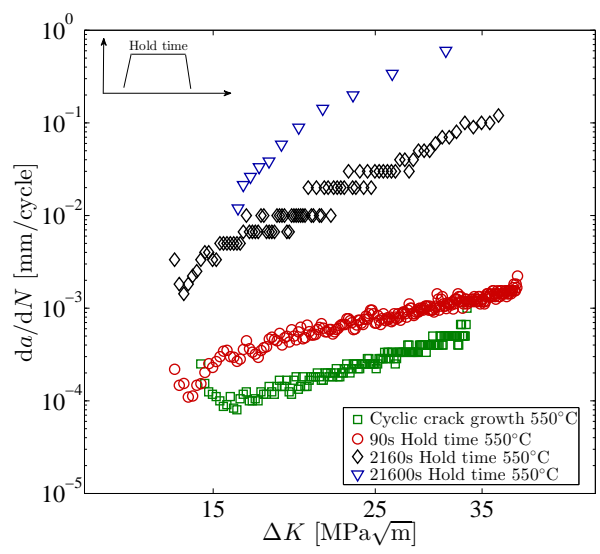

Figure 5: Hold time fatigue crack growth rates for $550{ }^{\circ} \mathrm{C}$.[23]

In the works above, and many others, the main microscopical discovery is that the crack grows in an intergranular fracture mode. This in opposite to cyclic fatigue crack growth, with enough high frequency to eliminate the hold time effect where, mainly transgranular fracture is seen, cf. Fig 6.

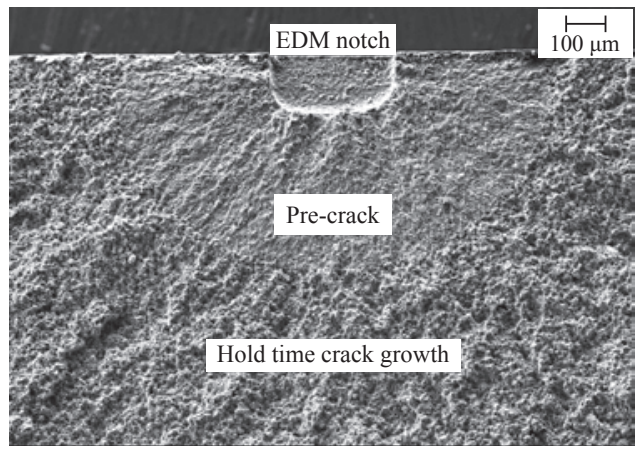

Figure 6: Fracture surface for a $2160 \mathrm{~s}$ hold time test at $550{ }^{\circ} \mathrm{C}$; areas indicating EDM notch, pre-crack and hold time crack growth region.

Other testing programmes have revealed that cracking is strongly affected by the environment, e.g. vacuum vs. oxygen, and it has been shown that a significant reduction in crack propagation rate is found in vacuum, see e.g. [24-29]. These tests and observations clearly show that the grain boundaries have been affected by some sort of mechanism which is not active in rapid cycling.

From these observations it becomes apparent that a regular fatigue cycle model will give inaccurate life time predictions for components exposed to hold times. 
Therefore, a number of attempts have been made to set up a hold time fatigue crack growth model, some more accurate and some more complicated than others.

\subsection{Hold time models}

The modelling of fatigue crack growth under hold time has been attempted by many authors. Most of them, e.g. [19, 22, 25, 30-32], rely on an additive description, where the contributions from hold times and cyclic loads are added together without any history dependence, see Eq. (4). There are, however, models which could be better. Such models are often based on physically motivated equations for e.g. diffusion, damage, crack closure, creep, alloy composition etc., where sometimes FE computations have been used/are needed for parameter determinations. Examples of such models can be found in e.g. [33-39]. These models can prove useful in the description of a hold time cycle, as they will also in some cases include history effects. However, the implementation and use of such models can require a high threshold in understanding for an everyday engineering problem, not to mention the time effort to calibrate the models by e.g. nodal release routines.

$$
(\mathrm{d} a)_{\text {tot. }}=\frac{\mathrm{d} a}{\mathrm{~d} N} \mathrm{~d} N+\frac{\mathrm{d} a}{\mathrm{~d} t} \mathrm{~d} t
$$

\subsubsection{Examples of different models}

Some of the existing models, found in various sources, will now briefly be presented. Emphasis is put on describing the basic features of the models and not going so much into details of e.g. the different parameters, and how they can be determined.

\section{Model by Saxena}

The model by Saxena [30] (see also [40, 41]), has been developed with respect to three crack growth regimes: (1) fully cycle dependent region, (2) intermediate region where both cyclic loads and hold times affect the total crack growth rate, and finally (3), which is the fully time dependent region, i.e. the crack growth is only affected by time dependent cracking. The model, which has been tested for various hold times, is given by Eq. (5) below for region (2), while the cyclic dependent regime (1) is given by an ordinary Paris law expression, see Chapter 3. When to apply the different crack growth region laws, is given by the transitional loading frequency, which is determined from experimental evaluation.

$$
\frac{\mathrm{d} a}{\mathrm{~d} N}=C_{1}(\Delta K)^{n_{1}}+C_{2}(\Delta K)^{n_{2}}\left(\sqrt{t_{\mathrm{h}}}\right)
$$


where $n_{1}, n_{2}, C_{1}, C_{2}$ are fitting constants, $t_{\mathrm{h}}$ is the hold time and where $\sqrt{t_{\mathrm{h}}}$ is related to the oxygen diffusion depth. The oxygen diffusion depth is derived from the postulated environmentally affected zone which affects the crack growth rate by its length, $l \propto \sqrt{D t_{\mathrm{h}}}$, where $D$ is a diffusion coefficient. As a result, $\mathrm{d} a / \mathrm{d} t=g\left(t_{\mathrm{h}}\right) K^{n_{2}}=\left[g\left(t_{\mathrm{h}}\right) \propto \mathrm{d} l / \mathrm{d} t_{\mathrm{h}} \propto \sqrt{D} / \sqrt{t_{\mathrm{h}}}\right]=\left(c / \sqrt{t_{\mathrm{h}}}\right) K^{n_{2}}$, where $\mathrm{c}$ is a constant. In fully time dependent loading, region (3), the following equation is used:

$$
\frac{\mathrm{d} a}{\mathrm{~d} N}=\frac{1}{\nu}\left(\frac{\mathrm{d} a}{\mathrm{~d} t}\right)_{\text {const. }}=t_{\mathrm{hold}} C_{\mathrm{time}} K^{n_{\mathrm{time}}}
$$

Model by Gayda et al.

Another linear summation model was proposed by Gayda [25], which is similar to the one by Saxena [30], see Eq. (7). The model has capabilities to handle slow ramp-ups to the hold time load, i.e. hold time damage is not longer only included in the sustained loading.

$$
\frac{\mathrm{d} a}{\mathrm{~d} N}=B \Delta K^{m}+A \Delta K^{n}\left[Z /(\nu(n+1))+t_{\text {hold }} /(1-R)^{n}\right]
$$

where $Z=\left(1-R^{n+1}\right) /(1-R)^{n+1}, R$ is the load ratio, $A, n, B, m$ are Paris parameters for time dependent and cyclic loading respectively, $t_{\text {hold }}$ is the hold time of a cycle, and where finally $\nu$ is the loading frequency of the ramp up and down to the hold time level.

Model by Kruch et al.

An LEFM-based modelling approach where the material parameters are calibrated by FE simulations has been suggested by Kruch [35]. Here a non-linear time dependent constitutive law is used to find closure parameters for various types of load cycles by a nodal release approach. The model is in its simplest form seen in Eq. (8). As seen, the model is a cycle per cycle linear summation model, thus introducing a load history dependence, where, e.g. overloads or (oxidation from) hold times, will affect the crack opening value obtained from numerical analysis.

$$
\mathrm{d} a=C_{\mathrm{F}}\left[K_{\mathrm{M}}-K_{\mathrm{S}}\right]^{\eta_{\mathrm{F}}} \mathrm{d} N+C_{\mathrm{c}}\left[K_{\mathrm{t}}-K_{\mathrm{S}}\right]^{\eta_{\mathrm{c}}} \mathrm{d} t
$$

where $C_{\mathrm{F}}, C_{\mathrm{c}}, \eta_{\mathrm{F}}, \eta_{\mathrm{c}}$ are material parameters, $K_{\mathrm{M}}$ is the maximum SIF value during a load cycle, $K_{\mathrm{S}}$ is the threshold value influenced by overloads, underloads, hold times etc. and obtained from the crack closure calibration (updated after 
and before a fatigue cycle) and $K_{\mathrm{t}}$ is the SIF value during a hold time. Examples of application to load spectrums and further explanations are found in [35], [34] where the model is extended to non-isothermal conditions and in [42] where the same model has been applied for the single-crystal superalloy AM1.

\section{Model by Evans and Saxena}

The model by Evans and Saxena [37, 39], also discussed in [41], and given by Eq. (9), consists of a number of parameters which will account for most mechanisms believed to affect for hold time damage.

$$
\begin{aligned}
& \left(\frac{\mathrm{d} a}{\mathrm{~d} N}\right)_{\text {tot. }}=q \Delta K^{n_{1}}+c_{0} \Delta K^{\mathrm{m}_{0}+\frac{c_{1}}{\mathrm{RT}}} \exp \left(-\frac{Q_{0}}{\mathrm{R}_{\mathrm{G}} \mathrm{T}}\right) \\
& +\int_{0}^{\mathrm{t}_{h}} A^{\prime \prime} \exp \left(-\frac{Q}{R_{G} T}\right) \exp \left[\Psi^{\prime}\left(\frac{1}{T}\right)\left(\frac{1}{t}\right)^{\frac{1}{\mathrm{n}+1}}\left(\frac{\Delta K}{1-R}\right)^{\frac{2}{\mathrm{n}+1}}\right] \mathrm{d} t
\end{aligned}
$$

where $q, n_{1}, \Psi^{\prime}, n$ and $A^{\prime \prime}$ are constants, $t$ is the time for a cycle, $Q_{0}$ is the activation energy for thermal activation of dislocations, $R$ is the load ratio, $Q$ is the activation energy between the environment and the alloy, $R_{G}$ is the universal gas constant, $T$ is the temperature, and finally $t_{\mathrm{h}}$ is the hold time. All the different parameters can be derived from four different tests at different conditions, e.g with different environments, temperature and loading frequency.

\section{Model by Ghonem and Zheng}

The model by Ghonem and Zheng [22] is based on the intergranular oxygen diffusion depth at the crack tip reached during the cycle effective oxidation time, which is dependent on the oxygen diffusivity of the grain boundaries, see Eq. (10). As a result, the model takes a more physical approach than the earliest linear summation models. Nevertheless, it is still a non-history dependent one which, in contrary to e.g. the one by Kruch [35].

$$
\begin{aligned}
\left(\frac{\mathrm{d} a}{\mathrm{~d} N}\right)_{\text {tot. }} & =\frac{\mathrm{d} a}{\mathrm{~d} N}+\frac{\mathrm{d} a}{\mathrm{~d} t} \\
\frac{\mathrm{d} a}{\mathrm{~d} t} & =\frac{\mathrm{d} a}{\mathrm{~d} N}+\int \dot{X}(\Delta K, t) \mathrm{d} t \\
\dot{X} & =G_{1}(t) \Delta K^{\mathrm{m}} \\
G_{1}(t) & =A t^{-a_{1}} \exp \left(-\frac{a_{2}}{t}\right)\left(1-a_{1}+\frac{a_{2}}{t}\right)
\end{aligned}
$$

where $m, A, a_{1}$ and $a_{2}$ are coefficients to be set. 


\section{Model in NASGRO}

The time-dependent models available in NASGRO [9] consist of two options, first a Paris model with time-dependent parameters, see Eq. (11), and the second an exponential function yielding almost the same result. For a more comprehensive comparison see [9].

$$
\frac{\mathrm{d} a}{\mathrm{~d} t}=A K^{n}
$$

The equation is stated to be valid for predicting the time-dependent behaviour in glass structures, e.g. windows and optical lenses. However, it is in its simplest form the same as the linear superposition model presented in Eq. (4).

\section{Model in DARWIN}

Time dependent cracking implemented in the DARWIN code, developed by Chan et al. [43], is based on an Arrhenius function, see Eq. (12) valid for constant frequency with dwell.

$$
\begin{aligned}
\left(\frac{\mathrm{d} a}{\mathrm{~d} N}\right)_{\text {dwell }} & =\left(\frac{\mathrm{d} a}{\mathrm{~d} N}\right)_{\text {cyclic }}+\left[t_{\text {dwell }}+1 / f\right]\left(\frac{\mathrm{d} a}{\mathrm{~d} t}\right) \\
\left(\frac{\mathrm{d} a}{\mathrm{~d} N}\right) & =A \Delta K^{n} \quad \Delta K>\Delta K_{t h} \\
\left(\frac{\mathrm{d} a}{\mathrm{~d} t}\right) & =\underbrace{B_{0} e^{-\frac{Q}{R T}}}_{B} K^{m}
\end{aligned}
$$

where $t_{\text {dwell }}$ is the hold time, $f$ is the loading and unloading frequency, $A, n, B_{0}$ and $m$ are constants, $R$ is the universal gas constant, $Q$ is the activation energy, and, finally, $T$ is the absolute temperature.

Note that this will give exactly the same model as in NASGRO, with the exception of $\left[t_{\text {dwell }}+1 / f\right]$ in DARWIN instead of $\left[t_{\text {dwell }}\right]$ in NASGRO. Thus, with fast load reversals, e.g. $0.5 \mathrm{~Hz}$ between each hold time load, the model can be simplified to the one found in NASGRO.

\section{Comparison between models}

The models discussed above are all developed for short hold times and often require special tests for calibration, sometimes in vacuum (tests required not performed within the testing programme executed in this thesis), or measurements of relaxation and crack opening by nodal release routines etc. As a result, none of them 
has been implemented and tested, with the exception of the models found in NASGRO and DARWIN which in their simplest form are only linear summation models. Such results are found in Chapter 6 where these models are compared to the one developed in the present work.

\section{Summary}

A first comment might be that the functions based on pure LEFM criteria are the most widely used. However, most of the models presented above are investigated for relatively short hold times and do not incorporate any history dependence, thus they are physically questionable, and those who do may be too time-consuming in calibration due to the FE usage. Questions should therefore be risen, whether a model based on pure LEFM can be modified so that a history dependence of the hold time effect can be incorporated. 



\section{Test programme}

To investigate the hold time behaviour of Inconel 718 a testing programme was initiated with the aim to provide relevant data for model set up, calibration, and microstructural studies. The test matrix initiated has been focused on $550{ }^{\circ} \mathrm{C}$, which is a relevant metal temperature for applications with Inconel 718 .

A common crack type, discovered by detection, is surface cracks, and therefore the test specimen chosen was a Kb-type specimen, as seen in Fig. 7a, with the cross section seen in Fig. 7b. On the rectangular cross section area of the test specimen an initial notch was generated using electro discharge machining (EDM), and from this a pre-crack was grown at room temperature in order to generate a sharp crack from which the actual test could be started, see Fig. 7c.

The crack length was monitored using the direct current potential drop (DCPD) technique where the potential drop across the crack due to a current led through the test specimen is measured through wires welded on each side of the crack. The further the crack advances through the material the larger the potential drop will be, since the resistance in the test specimen will increase as the still active cross-sectional area decreases. In order to keep the scatter down, a normalised PD value was used, this by welding two reference wires on the back of the specimen, in which the current will travel the same distance throughout the complete test. A typical welded test specimen is shown in Fig. 8, with a welding on each side of the notch, and where also a predicted crack path is drawn. The different tests were all run in an MTS servo hydraulic machine with a furnace to provide for correct temperature.

After a test has been completed crack growth data is to be evaluated, e.g. $\mathrm{d} a / \mathrm{d} N$ and $\Delta K$. This is done by taking the $\mathrm{PD}$ data and comparing it with a pre-defined calibration curve which has been experimentally derived. The calibration curve is taken from visible beach marks on a test subjected to pure cyclic loading at different temperatures which produces different colours on the fracture surface. Then, with the calibration curve, the data is processed by an in house Matlab code to extract the crack growth rate and the stress intensity factor; more details about the code and the related evaluation method can be found in $[17,46]$. 

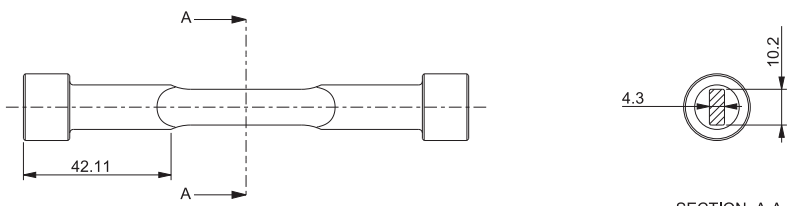

SECTION A-A
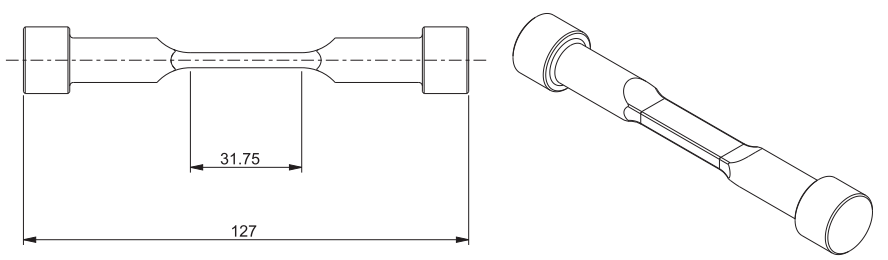

(a)

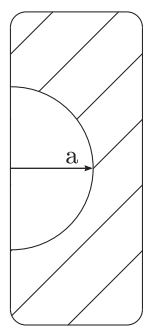

(b)

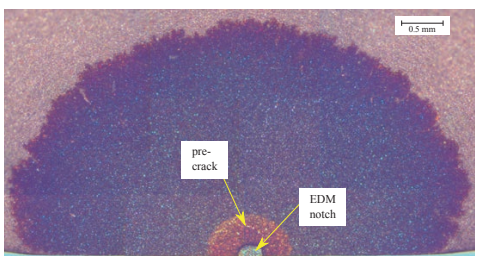

(c)

Figure 7: Test specimen used. (a) Drawing of a Kb test specimen, dimensions in $\mathrm{mm}$, (b) cross section A-A with indicated crack length and (c) post-mortem fracture surface.[44, 45]

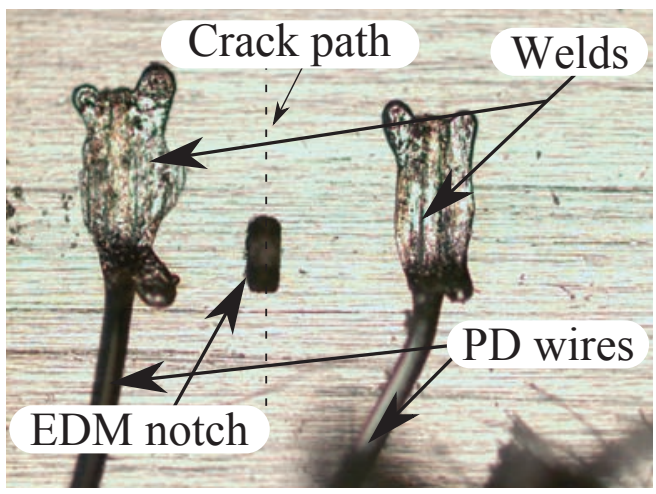

Figure 8: PD welds surrounding a starter notch with a potential crack path, i.e. the image was taken before the test was initiated. 


\section{Modelling work}

Even though the number of different models has increased substantially over time, it is hard to find a model which fulfils the requirements:

- It should be valid over a vide range of hold times, i.e. for sustained loads from a few seconds to a sustained load test with no load reversals.

- It should require few input parameters and thereby be easy to calibrate.

- It should function or be modified to function over a vide range of conditions

a non-isothermal

b varying load ratios

c overloads/underloads

- It should be easy to use on a daily basis as an engineering tool for practical use, thus being compatible/with some modifications useable, with already developed fatigue life software.

A reliable model with the above features will be of high value for life prediction analysis of components. Below the outline of the physical basis for the model will be presented.

\subsection{Damage mechanisms}

Based on the observations in Chapter 4, i.e. that hold times affect the fracture behaviour of the material causing intergranular cracking (increasing crack growth rate) instead of transgranular, as mainly seen for rapid cyclic loading, theories for the damage evolution have been developed. Many authors have tried to describe the mechanism and how it affects the grain boundaries, and two dominating theories has been developed, namely dynamic embrittlement (DE) and stress accelerated grain boundary oxidation (SAGBO), describing different ways in which oxygen (among other embrittling elements) affects the grain boundaries. DE is a cracking process where embrittling elements (e.g. oxygen) weaken the grain boundaries, and allow for further crack advancement as they crack, see e.g. [15, 18, 27]. 
SAGBO, on the other hand, involves oxidation of grain boundaries and the subsequent cracking of these oxides, allowing for further crack advancement, see e.g. [28]. The active mechanism will leave stronger grain boundaries behind, thus leaving unbroken ligaments and islands of unbroken material, which can also be seen when breaking open specimens and investigating the fracture surface [18, 47].

\subsection{Observation of unbroken ligaments - damaged zone}

From the section above it becomes apparent that left-overs of unbroken material are present behind the front of damaged material, as some areas have a higher resistance against the breaking of grain boundaries. These ligaments and islands with unbroken material left behind can be observed in potential drop measurements $[44,45]$ as these are also electrically conductive [48]. Alternative measurement techniques, e.g. by compliance, have confirmed the same observations, crack lengths are underestimated compared to measurements on the fracture surface [19]. However, it is important to note that the mechanism seen has been shown to function on a nanometre scale [49]. This area is therefore sometimes mistakenly seen as the region where the mechanisms function, i.e. from completely broken to completely unbroken material. The area with left overs has in many different works been seen to stretch over very long distances, up to a mm scale depending on, e.g., temperature, hold time, material and type of test specimen, cf. [20, 44], distances at which the diffusion processes would be rendered inoperative. It is this area, between the completely unbroken area and the one registered by $\mathrm{PD}$, which in this work is consequently denoted as the damaged zone, see Fig. 9.

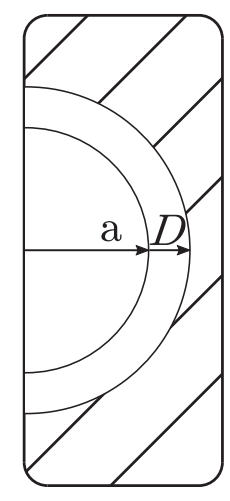

Figure 9: Crack length a and damaged zone $D$ marked on the fracture surface of a Kb-specimen. [44]

In all tests the cracked area was evaluated through a calibration curve, derived from a pure cyclic test by measuring induced beach marks on the fracture surface. 
Since this method only considers fully cracked areas (or areas with low amount of ligaments and islands), it will for hold time tests not include the damaged zone, seen as the final crack length on a post-mortem fracture surface for, e.g., a pure hold time test. The damaged zone may be measured by initiating a cyclic block of rapid cycling after a hold time block where, when the baseline level is reached, the damaged zone of unbroken material has been completely through cracked by the rapid cycling, see Fig. 10 for 550 and $650{ }^{\circ} \mathrm{C}$ [44, 45]. That is, during the rapid cycling no damaged zone build-up is gained. This gives an approximate prediction of the zone as the 1D context determines an equivalent length, i.e. one is not given any information on how the crack length and damaged zone evolution look like in each direction on the fracture surface. Measurement on post-mortem fracture surfaces has been done in [45] and has been shown to give almost equivalent results with the method mentioned previously, seen in Fig. 10.

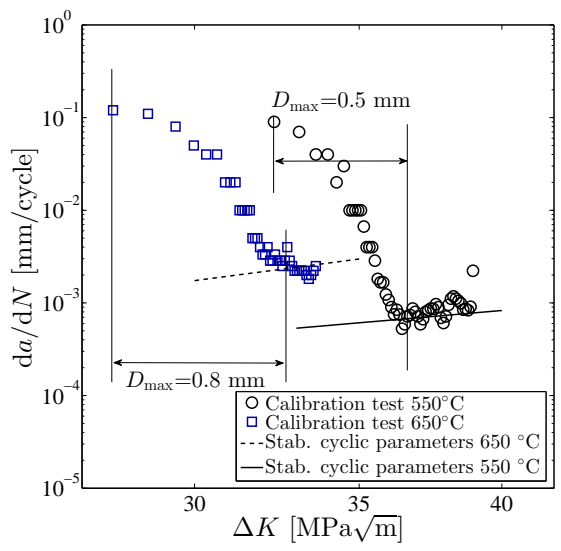

Figure 10: Crack propagation rates for a hold time test interrupted by a cyclic block, 550 and $650{ }^{\circ} \mathrm{C}$. [44, 45]

Although one can clearly observe and measure the damaged zone in Fig. 10, it is not as easy to see it in a microscope. Observations have been made by scanning electron microscope (SEM) to try to observe the unbroken ligaments and islands of unbroken material. These have, however, not shown the results one would expect. Rather than showing a lot of unbroken ligaments, which on a fracture surface should be identified with regions of ductile fracture, almost entirely intergranular fracture is seen. However, one can see how the crack has grown through the material in a finger-like behaviour, i.e. grain boundaries which are weaker than others are more prone to fracture first, as the mechanism affects the grain boundaries. The stronger grain boundaries are left behind and hold the fracture surfaces together, but as time passes, the grain boundaries left behind will also be affected. Finally, as a test specimen is broken apart and investigated, most of the ligaments will be fractured intergranularly, most probably due to the fact that the force required to break a 
grain boundary is much less in the affected grain boundaries than in an unaffected crystal structure, see Fig. 11 where the above process is summarised. Note that this description is only one possible hypothesis of how the process might work, although likely through the observations in test data and through microscopy studies. To truly confirm the process and the content in Fig. 11 more microscopy work needs to be carried out, which is scheduled within the future frame of the project. Also note that the present study only involves Inconel 718, whereas other materials might show different microstructural behaviour, e.g. depending on ductility, alloy composition etc. which might affect the resistance to the damaging mechanisms.

However, at the very front of the crack, seen as final fracture, there will exist grain boundaries which have been exposed to the embrittling element for a shorter time, and which will thus fracture by ductile mode as the test specimen is eventually broken apart. To study this, a sustained load test run at $550{ }^{\circ} \mathrm{C}$ was used. The test was both examined by optical microscope and by SEM to detect the areas where the crack has passed, in order to strengthen the hypothesis about the damaged zone evolution. The fracture surface is seen in Fig. 12 where three areas of visible ductile fracture can be found, denoted 1,2 and 3; these were investigated in depth to be analysed in detail in Fig. 13 and 14. Black areas seen in Fig. 12 are due to carbon pollution. For more material and further examples, the reader is referred to, e.g., [45]. 


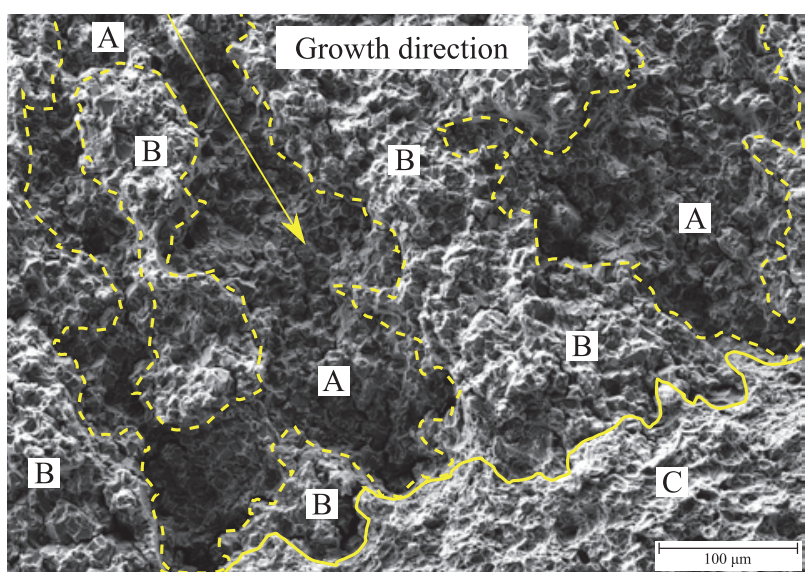

Figure 11: Post-mortem fracture surface with visible fingers where the damage mechanism has been most prone to affect the grain boundaries, marked as area (A), not so affected grain boundaries, but still fractured in intergranular mode are marked by (B), final fracture is marked by (C), i.e. ductile fracture with visible dimples. Also including the crack growth direction.

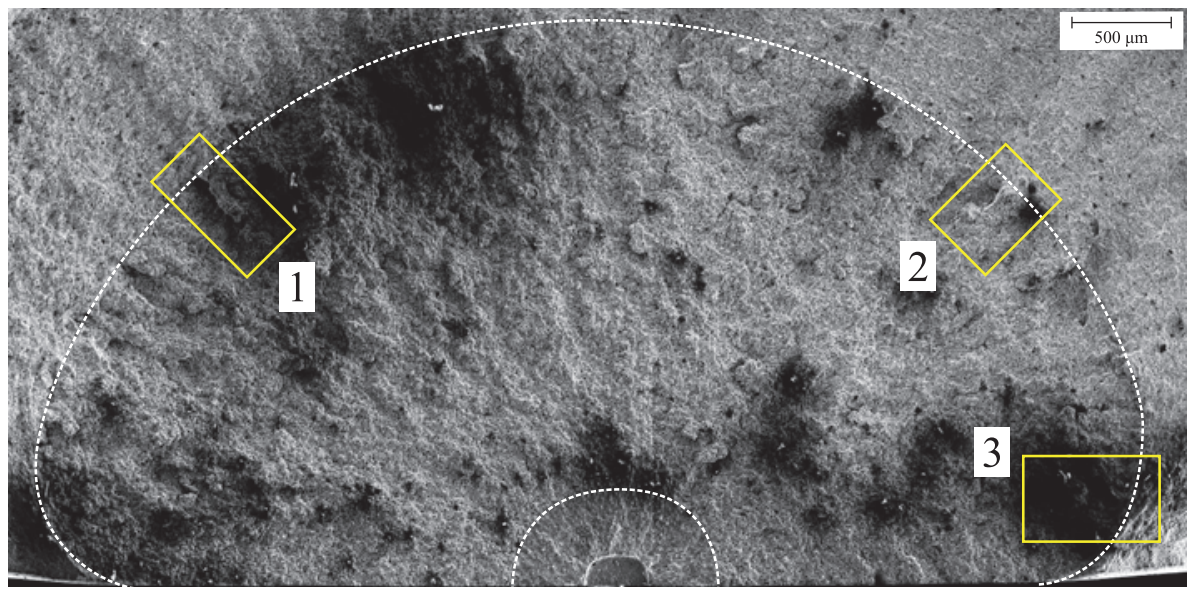

Figure 12: Fracture surface for the pure hold time test at $550{ }^{\circ} \mathrm{C}$. The areas marked 1, 2 and 3 are shown and explained in detail in Fig. 13 and 14, carbon pollution identified seen in the black areas.[45] 


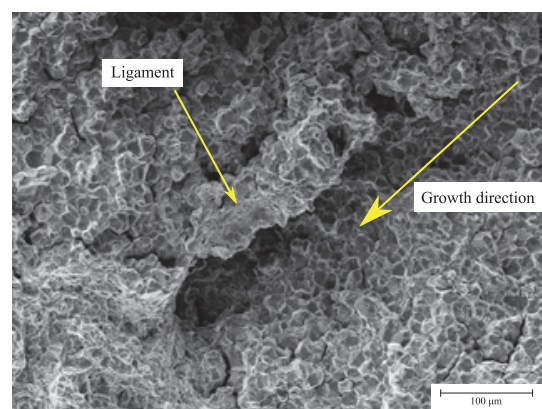

(a) area 1

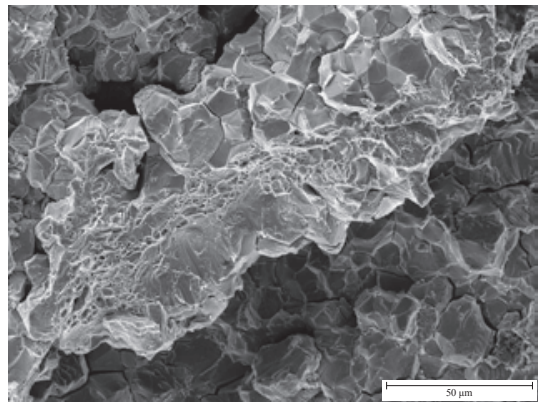

(c) area 1

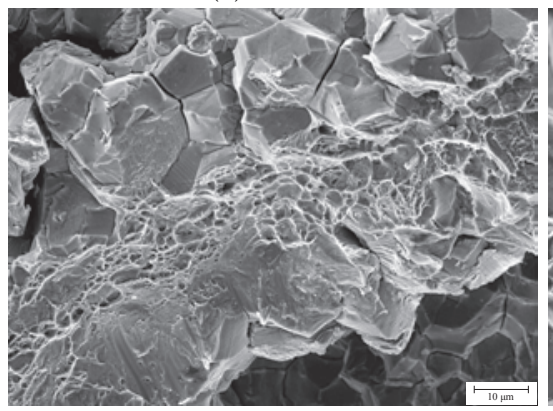

(e) area 1

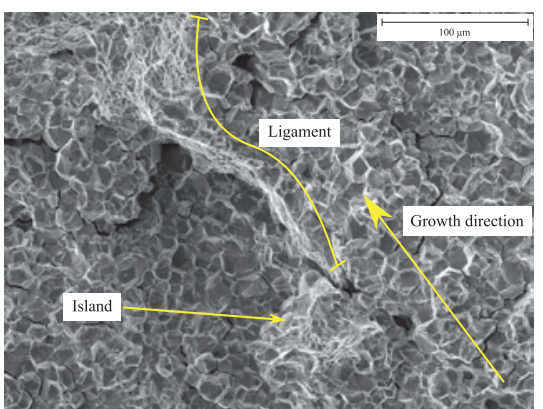

(b) area 2

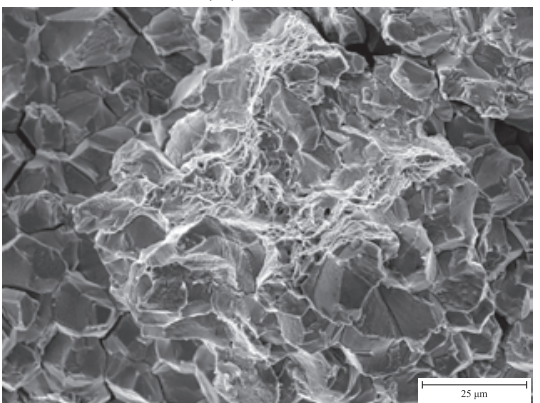

(d) area 2

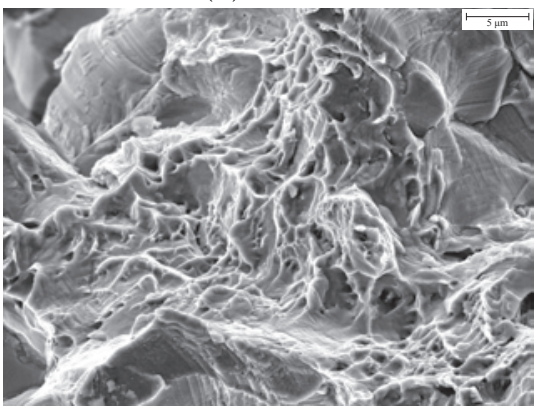

(f) area 2

Figure 13: Zoom-in on area 1 and 2 in Fig. 12, visible ductile fracture in ligaments in the final damaged zone. (a) Overview with global crack growth direction, (b) overview with global crack growth direction, (c) zoom-in with visible ductile fracture, (d) zoom-in on the island with visible ductile fracture, (e) further zoom-in with visible dimples and (f) further zoom-in on the island with visible dimples.[45] 


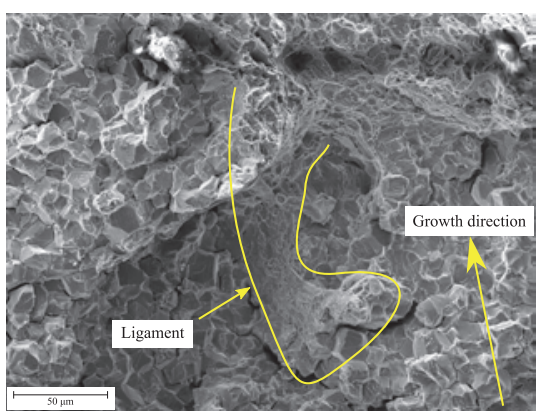

(a)

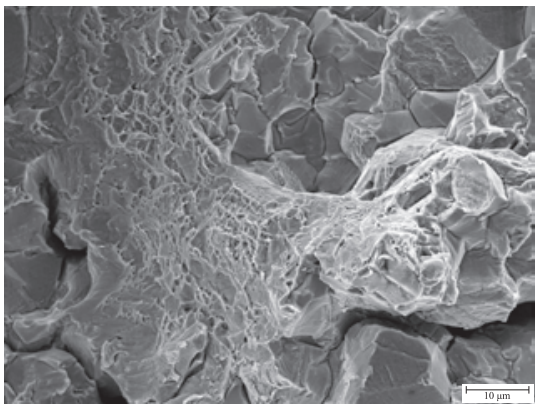

(b)

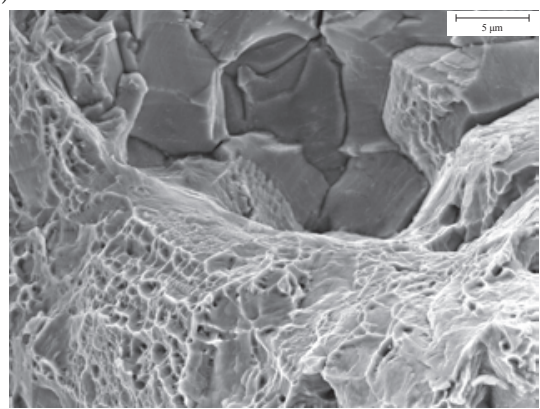

(c)

Figure 14: Zoom-in on area 3 in Fig. 12, visible ductile fracture in one ligament in the final damaged zone. (a) Overview with global crack growth direction, (b) zoomin with visible ductile fracture and (c) further zoom-in with visible dimples.[45]

\subsection{The basis of the model}

The fatigue crack propagation model developed is based on the damaged zone concept discussed above. The physical description involves how the damaged zone is built up during the hold times and consumed during load reversals, but not on a physical level which exactly describes how the grain boundaries are weakened. During the build-up of the zone the time-dependent crack growth rate $\mathrm{d} a / \mathrm{d} t$ increases as the damaged zone increases, and as the damaged zone is decreased, i.e. the ligaments are broken apart, the cyclic crack growth rate $\mathrm{d} a / \mathrm{d} N$ is also increased. Eventually, as the damaged zone is completely "consumed" the crack growth rate, $\mathrm{d} a / \mathrm{d} N$, is back on baseline level. The whole concept will therefore include a history-dependent description and will rely on "on the fly" cycle counting, i.e. the crack will grow differently depending on where in the load history one applies a hold time or a load reversal.

This modelling approach differs from others discussed in Chapter 4 as the crack 
growth will depend on the damaged zone build-up and destruction. Thus, the main contribution that is not seen in any existing models found by the author, is the history dependence of how the crack develops when it is exposed to hold times, which is a major advantage when applying load spectrums experienced by actual gas turbine components.

\subsubsection{Damaged zone build-up}

The damaged zone build-up is the first important aspect of the model's capability of accurate life prediction. When studying a pure hold time test, one observes the following things:

1. An initiated incubation time, cf. [18, 27, 50], where almost no crack growth is seen. The damaged zone is in its build up phase, i.e. starting to affect the grain boundaries, see Fig. 16. The same thing can be seen after a load reversal has been applied, when the crack growth is halted for some time, cf. Fig. 15 where a test from [44] is seen. The incubation time is seen to be the time before the crack growth rate picks up time after a load reversal.

- One possible explanation of the observed behaviour could be that when a load reversal is applied, the oxygen supply paths will be affected/blocked, thus slowing up the damage rate. As a result, there is seen some incubation time after a load reversal as well as in the beginning of the test, i.e. when the mechanism acts on totally unaffected material.

2. Once the grain boundaries have begun to break apart (the weakest grain boundaries in the material), and begin to "dig" into the material, seen as fingers in Fig 11, the crack gains some speed as the process continues.

3. As the crack advances through the material it will eventually reach a stable phase, where the crack is growing at the same rate as the damaged zone is built up, this is seen as a straight line in a $\log -\log$ diagram da/d $t$ over $K_{\max }$, see Fig. 16. 


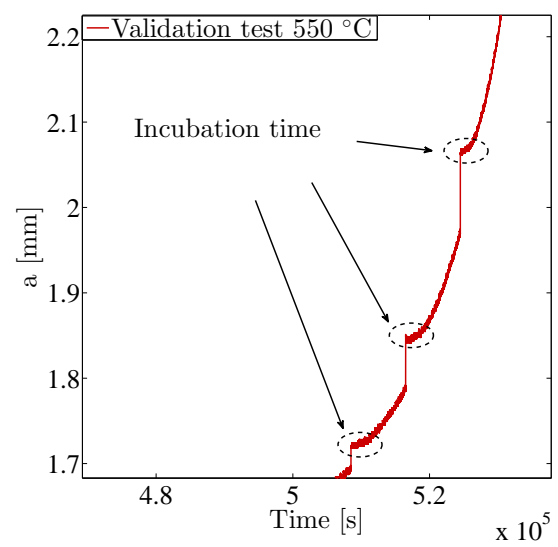

Figure 15: Test with hold times mixed with load reversals, indication of incubation time after load reversals, a zoom-in on Fig. 19.[44]



Figure 16: Time dependent tests with stabilised values. Increasing crack growth rate as the damaged zone is built up, and stabilised crack growth is reached when the damaged zone is fully developed to its stabilised value.

However, although a stabilised damaged zone level is reached in the above tests, also confirmed to be $K$ independent [45], it is most likely that the damaged zone is geometry-dependent. As mentioned in [45] that due to the tunnelling effect (i.e. the crack grows slower on the surface than on the depth), caused by the plane strain/stress relation of the test specimen, fully plane strain tests would probably give the fully stabilised langth of the damaged zone (work in progress). 


\subsubsection{Damaged zone consumption}

When applying fast load reversals, i.e. at a frequency high enough to cause a time independent cracking, the damaged zone is consumed as the crack front propagates through. Thus, this will increase the crack propagation rate compared to the base line level, see Fig. 10, since the fracture surfaces within the damaged zone are only held together by weakened ligaments of unbroken material. The further the crack propagates through the damaged zone the less will remain, which will in turn decrease the cyclic crack propagation rate. The opposite will of course happen during the build up of the zone, where one reaches a stabilised state of fully developed damaged zone.

\subsection{Crack propagation law}

When examining the concept of the damaged zone build-up, it can be concluded that the evolution of it depends on the mechanism at the edge of undamaged material and that this mechanism depends on the length of the zone itself. As a result, the mechanism will affect the crack growth rate less when the zone is small and when it grows longer it affects the growth rate more. Consequently, as a load reversal is applied and "consumes" a part of the zone, the mechanism will have a smaller effect. Once the damaged zone is built up once more, the mechanism will continue to accelerate. The phenomenological modelling concept is supported by many experimental results, and although it lacks a pure physical description of how the mechanism affects the grain boundaries, it do seem to capture the mechanism/damaged zone realistically.

Nevertheless, by these observation the governing equations for the crack length and damaged zone evolution, can be set up. The crack propagation law will due to the evolution of the damaged zone and its effect on the crack length be history dependent, see Table 3, which describes the complete crack growth law, including the damage zone equations. 
Table 3: Crack growth law.[12, 44, 45]

Time dep. crack growth rate:

Time dep. scale function:

Time dep. damaged zone growth rate:

Damage mechanism growth rate:

Cyclic crack growth:

Cyclic damaged zone evolution:

Cyclic scale function:

$$
\begin{aligned}
& \dot{a}_{t}=\frac{D}{D_{\max }} \cdot C_{t} K_{\max }^{n_{t}} \\
& C_{t}=C_{0 t}\left(1-\exp \left(\frac{-B_{t}}{1-\frac{D}{D_{\max }}}\right)\right) \quad B_{t} \geq 0
\end{aligned}
$$

$\dot{D}_{t}=\dot{m}-\dot{a}_{t}$

$$
\dot{m}=C_{t} K_{\max }^{n_{t}}
$$$$
\Delta a_{c}=\int_{t_{1}}^{t_{2}} \dot{a}_{c} \mathrm{~d} t=\int_{0}^{1} \frac{\mathrm{d} a_{c}}{\mathrm{~d} N} \mathrm{~d} N
$$$$
\frac{\mathrm{d} a_{c}}{\mathrm{~d} N}=S_{c} \cdot C_{c} \Delta K^{n_{c}}
$$$$
\Delta D_{c}=\int_{t_{1}}^{t_{2}} \dot{D}_{c} \mathrm{~d} t=\int_{0}^{1} \frac{\mathrm{d} D_{c}}{\mathrm{~d} N} \mathrm{~d} N
$$$$
\frac{\mathrm{d} D_{c}}{\mathrm{~d} N}=-\frac{\mathrm{d} a_{c}}{\mathrm{~d} N}
$$

$$
S_{c}=1+A_{c}\left(\frac{D}{D_{\max }}\right)^{B_{c}} \quad A_{c}, B_{c} \geq 0
$$

In the crack growth law of Table 3, $a$ is the crack length, $D$ is the damaged zone length, $m$ is the damaged mechanism, and finally, subscripts $c$ and $t$ describe cyclic and time dependent crack growth respectively. More information about the respective equations can be found in [44].

The proposed crack propagation law has so far proven to show reasonable results, cf. [44], for various temperatures and hold times, from $90 \mathrm{~s}$ in each cycle up to pure hold time crack growth, see below.

\subsubsection{Results}

Some of the tests run within the test programme will now be evaluated and results compared with the linear summation model in Eq. (4) of Chapter 4, which is similar to the ones in NASGRO and DARWIN. Thus, the model compared to the one proposed in Table 3 is presented in Table 4.

As focus has been placed on $550{ }^{\circ} \mathrm{C}$, some typical cycle types are considered to represent the performance of the model, i.e. $90 \mathrm{~s}$ HT in Fig. 17a, sustained load test in Fig. 17b, and finally a 2160 s HT seen in Fig. 18. 
Table 4: Linear summation model, see Eq. (4) in Chapter 4.

Time dep. crack growth rate: $\dot{a}_{t}=C_{t} K_{\max }^{n_{t}}$

Cyclic crack growth:

$$
\begin{aligned}
& \Delta a_{c}=\int_{t_{1}}^{t_{2}} \dot{a}_{c} \mathrm{~d} t=\int_{0}^{1} \frac{\mathrm{d} a_{c}}{\mathrm{~d} N} \mathrm{~d} N \\
& \frac{\mathrm{d} a_{c}}{\mathrm{~d} N}=C_{c} \Delta K^{n_{c}}
\end{aligned}
$$

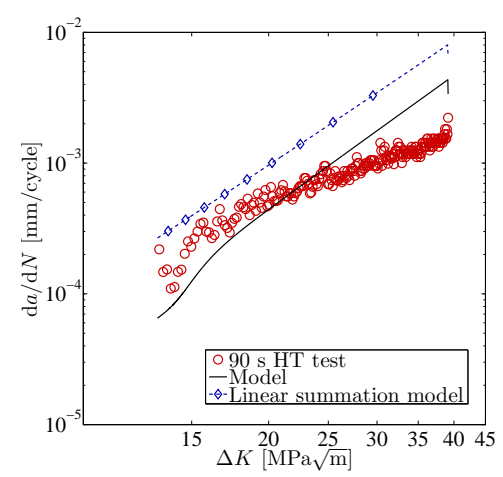

(a)

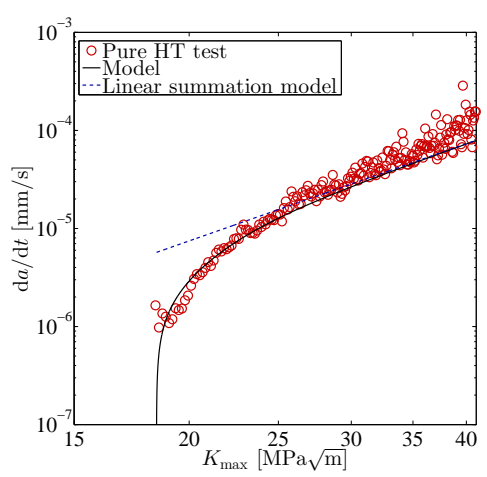

(b)

Figure 17: Comparison between models. (a) Model in Table 3 vs. 4 evaluated to a $90 \mathrm{~s}$ hold time test at $550{ }^{\circ} \mathrm{C}$ and (b) a sustained load test at $550{ }^{\circ}$ compared to the model in Table 4.

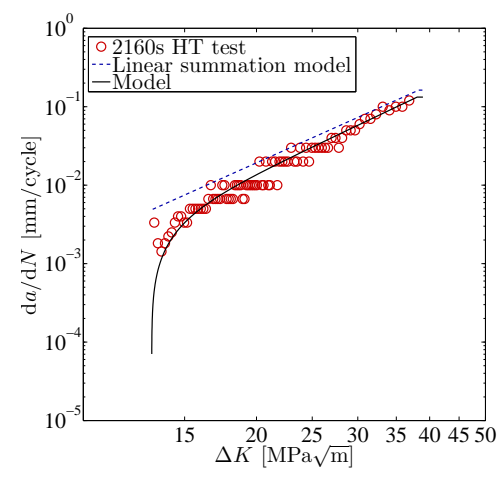

(a)

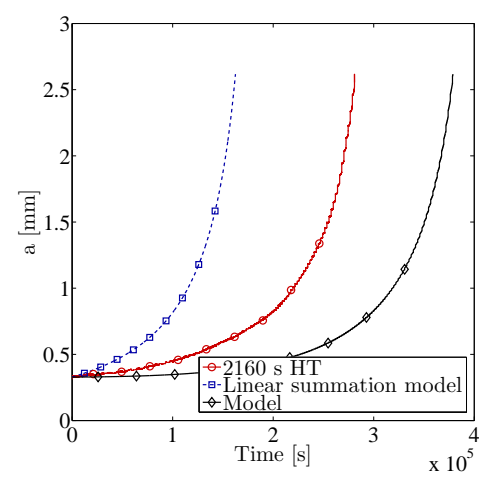

(b)

Figure 18: Comparison between models on a $2160 \mathrm{~s}$ HT test at $550{ }^{\circ} \mathrm{C}$. (a) d $a / \mathrm{d} N$ vs. $\Delta K$ and (b) crack length vs. time. 
In the beginning of a test the most striking difference is seen between the developed model and the linear summation model in Table 4, as an incubation time is seen for the crack growth rate to pick up speed to approach the stabilised value for each test. After a load reversal the crack growth rate is exposing a small incubation time, which will make the crack growth halt for a moment. Also note the increase in crack propagation rate as a load reversal is applied. None of these features are given by the model in Table 4 and similar linear summation models spoken of before in Chapter 4. One may however think that these features are not necessary as a reasonable crack growth rate is within scatter limits, cf. [44]. Therefore, to show the benefits of the model performance a slightly more complicated spectrum was tested from [44] where some hold times of varying length are intercepted by various load reversals, see Fig. 19. It is here obvious how the developed model will be beneficial in life prediction of more complicated spectrums

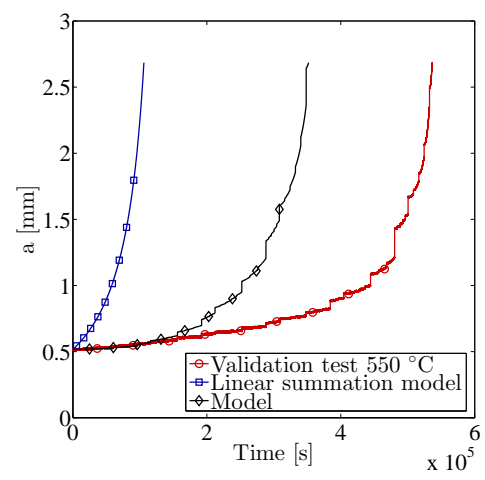

Figure 19: Test from [44] where a number of hold times are mixed with load reversals, modelling comparison to Table 4.

To further demonstrate the benefits of the damage-zone model, an application-like flight spectrum of a typical component subjected to hold times mixed with various load reversals of various load ratios has been studied. Here the model by Newman [10] discussed in Chapter 3 has been added to provide for correct crack closure behaviour for subsequent interaction with the hold times. In Fig. 20 below, the model is compared with a more classical approach with no history dependence (with $C_{t}=C_{0 t}$ and $\dot{a}_{t}=C_{t} K_{\max }^{n_{t}}$ on each time dependent part and $D=0$ on each cyclic part), i.e. the model in Table 4 , and with a model with no hold time effect added (here with $\sigma=0$ on the hold time parts). The damaged-zone model can be seen to be very accurate compared to the other two and, as a result, it should have potential for use in an industrial context. 


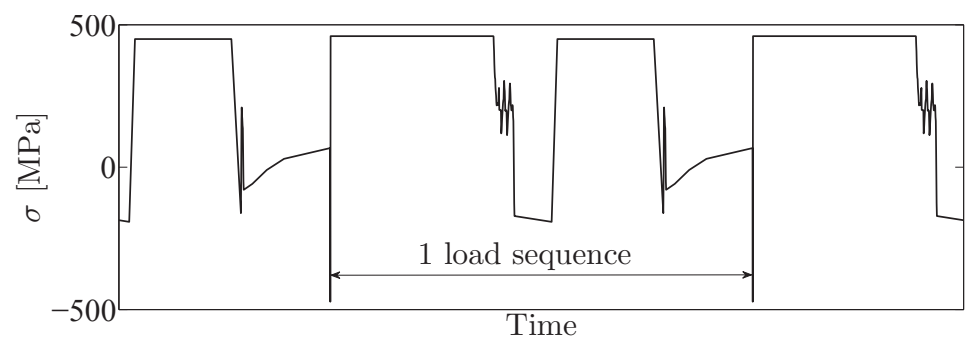

(a)

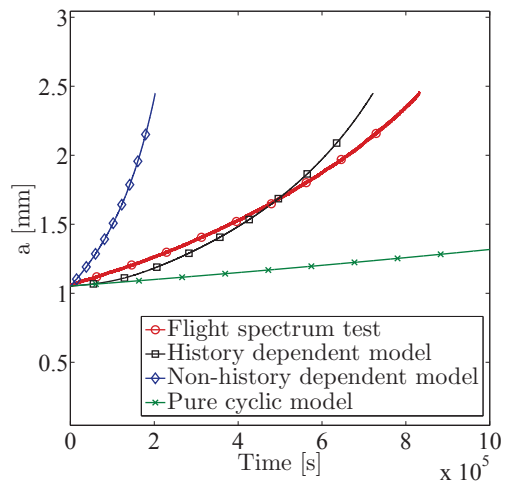

(b)

Figure 20: Flight spectrum. (a) Load sequence and (b) crack length vs time, with different modelling approaches, blue diamonds indicating the model in Table 4.[12] 


\section{Future work}

In the work completed so far in this project much attention has been given to establishing relevant fatigue crack propagation models for hold time conditions. The model which has been found works very well for what type of loads, temperatures etc. it has been developed for. However, further work is still needed in order to establish a description valid under more general aspects. One major issue which has to be dealt with is the lack of validation data for other test specimens, or other crack geometries, e.g. a through crack instead of a surface crack. So far, the model has only been applied under one-dimensional conditions, which is also the case for many other models found in the literature. However, this is not the case in everyday situations. This will probably be one of the most important factors in order to make it applicable for structural problems found in an industrial context. As the project continues, this will be a topic for further investigation.

Another issue which has to be addressed is that the hold time cycles, with only some minor exceptions, have been of the extreme type $\dot{\sigma}=0$, which is far from the only hold time condition seen in the gas turbine applications. Attention should also be given to hold times with varying load, e.g. ramp up of engine thrust, slow shut downs, cyclic loading with very low load frequency etc. These hold times are in the present model not possible to simulate reliably, as no investigation of how the damaged zone concept should be applied to these situations has been done. Thus, one has to investigate if a threshold frequency for damaged zone build-up exists and, if so, how large it is; and when destruction of the damage zone takes place. Some studies have been performed for investigating the frequency behaviour for loading under hold times. However, work is still needed to incorporate this into the damaged zone concept.

The problem of the applied loading can also be linked to issues of spectrum complexity, as much attention has been given to how important the load history may be for a component. So far only a small part has focused on the overload phenomena. Here, as with many other complex loading types more work has to be done. The introduction of underloads, negative $R$ ratios, other overload and TMF etc. imply that testing must be continued in order to gain access to information yet hidden for a more complex model development.

Different materials is also a topic for further work, since so far only Inconel 718 in wrought form has been considered. Here, much research is needed on how the 
existing model can be applied.

The model has thus proven to be reliable in many of the tests for which it has been applied, ranging from short hold times to pure sustained load tests with no load reversals, and combinations with the interaction of rapid cyclic loading with a variety of $R$-values. Thus, at the present state the model should be able to prove itself useful for some simple industry-relevant problems, as shown with the validation of the flight spectrum presented in one of the included papers. 


\section{Review of included papers}

\section{Paper I}

\section{High temperature fatigue crack growth behaviour of Inconel 718 un-}

der hold time and overload conditions

The fatigue crack propagation behaviour of Inconel 718 with and without hold times has been studied for $550^{\circ} \mathrm{C}$ and $650^{\circ}$. In addition to this, hold time tests with and without initial overloads in each hold time cycle has been studied for 550 ${ }^{\circ} \mathrm{C}$. The initial overloads had a major influence on the crack propagation rate, and the cause of this is believed to be the stress state in front of the crack tip. To investigate the cause, a simple 2D FE model was set up to show how the stress field is affected by an overload. Further, a fatigue crack propagation model was developed to cope with the overload effect, the model was based on the concept of a damaged zone in front of the crack tip caused by the hold time load, which was also confirmed by a brief microscopy study of the crack front.

\section{Paper II}

Modelling of high temperature fatigue crack growth in Inconel 718 under hold time conditions

The paper focuses on the modelling of fatigue crack propagation under hold time conditions at $550{ }^{\circ} \mathrm{C}$, including a damage mechanism acting in front of the crack tip. The damaged zone concept is used with applied scale factors for the build-up of the zone during hold times, and subsequent destruction during load reversals. The concept was successfully applied in the time dependent regions (i.e. for long enough hold times), for a variety of different load sequences (hold time tests, block tests and pure time dependent tests). 


\title{
Paper III
}

\author{
A load history dependent model for fatigue crack propagation in In- \\ conel 718 under hold time conditions
}

Further development of the fatigue crack propagation model which was presented in Paper II has been conducted. The model has been extended by a description of the hold time behaviour which includes an additional term to handle the incubation time commonly seen during the initial part of a hold time test. As a result, the modelling concept is now able to handle both short and long hold times. The incubation time term serves as a description of how the damaged zone is initially built up. However, the model contains the same number of fitting parameters as the model in the previous paper. In addition to this, an efficient calibration method was developed for parameter identification, which was successfully shown for 550 , 600 and $650{ }^{\circ} \mathrm{C}$. With the new modelling concept and calibrated parameters, a total of 22 different tests were investigated, some of which were tests that had already been published, whereas others were new validation tests developed for this paper. The results were then used for statistical evaluation, which showed that the model gives a reasonable scatter factor at a probability of failure of $0.1 \%$.

\section{Paper IV}

\author{
Modelling of fatigue crack growth in Inconel 718 under hold time \\ conditions - application to a flight spectrum
}

To validate the model under more application-like conditions a flight component spectrum was used for this study. The spectrum was run under isothermal conditions at $550{ }^{\circ} \mathrm{C}$ and involved a variety of different load ratios and hold times. To process the spectrum information, a manual evaluation method was used to identify individual cyclic parts and hold time parts. In order to simulate this, the model developed in the previous paper was extended by the crack closure routine by Newman [10]. The result shows good correlations to test data, which also confirms how the damaged zone concept can be used for prediction of the life of actual components. To further show the benefits of the model a comparison to a non-history-dependent model was made on the same spectrum, where the latter not surprisingly underpredicts the time to final crack length. 


\section{Paper V}

\section{Evaluation and prediction of crack length in a Ni-based superalloy for sustained loading}

In this paper, the model developed in the previous papers for 550 and $650{ }^{\circ} \mathrm{C}$ has been used, together with post-mortem fracture surfaces, to show how crack length and damaged-zone evolution over time can be evaluated. The findings show how the zone is built up during hold times and rapidly decreases during load reversals as the crack length "seen" by the PD-method increases. In addition, the fracture surfaces are investigated and equivalent crack lengths are determined to compare with the potential drop signal. This shows that the damaged zone must be taken into consideration when evaluating and setting up post-mortem reference curves for crack length evaluation, and in the development of history-dependent crack propagation models. Finally, the paper includes further evaluation of the damaged zone by identification of it on fracture surfaces for two sustained load tests at 550 ${ }^{\circ} \mathrm{C}$. Here a scanning electron microscope (SEM) study was completed for the two fracture surfaces, and findings show the structure of the damaged zone is most likely constructed. 



\section{Bibliography}

[1] M Durand-Charre. The microstructure of superalloys. Gordon and Breach Science Publishers, 1997.

[2] http://www.turbokraft.se.

[3] C.T. Sims, N.S. Stoloff, and W.C. Hagel. Superalloys II. Wiley-Interscience, 1987.

[4] J.R. David, editor. Heat-Resistant Materials. ASM International, 1999.

[5] R.C. Reed. The Superalloys - Fundamentals and Applications. Cambridge University Press, 2006.

[6] P. C. Paris, M. P. Gomez, and W. E. Anderson. A rotational analytic theory of fatigue. The Trend in Engineering, 13:9-14, 1961.

[7] P. C. Paris and F. Erdogan. A critical analysis of crack propagation laws. Journal of Basic Engineering, 85(4):528-534, 1963.

[8] W. Elber. Fatigue crack closure under cyclic tension. Engineering Fracture Mechanics, 2:37-45, 1970.

[9] NASGRO manual 6.0, SwRI.

[10] J.C. Newman Jr. A crack opening stress equation for fatigue crack growth. International Journal of Fracture, 24:R131-R135, 1984.

[11] M. Hörnqvist and T. Månsson. Fatigue crack growth in Ti-6242 under elastoplastic loading conditions. Procedia Engineering, 2(1):223 - 229, 2010. Fatigue 2010 .

[12] E. Lundström, K. Simonsson, T. Månsson, and D. Gustafsson. Modelling of fatigue crack growth in Inconel 718 under hold time conditions - application to a flight spectrum. Advanced Materials Research, 891-892:759-764, 2014.

[13] E. Andrieu, R. Molins, H. Ghonem, and A. Pineau. Intergranular crack tip oxidation mechanism in a nickel-based superalloy. Materials Science and Engineering: $A, 154(1): 21-28,1992$.

[14] H. Ghonem, T. Nicholas, and A. Pineau. Elevated temperature fatigue crack growth in alloy 718-part II: Effects of environmental and material variables. 
Fatigue $\&$ Fracture of Engineering Materials \& Structures, 16(6):577-590, 1993.

[15] J.A Pfaendtner and C.J McMahon Jr. Oxygen-induced intergranular cracking of a Ni-base alloy at elevated temperatures - an example of dynamic embrittlement. Acta Materialia, 49(16):3369 - 3377, 2001.

[16] F. V. Antunes, J. M. Ferreira, C. M. Branco, and J. Byrne. Influence of stress state on high temperature fatigue crack growth in Inconel 718. Fatigue 68 Fracture of Engineering Materials 85 Structures, 24(2):127-135, 2001.

[17] D. Gustafsson, J.J. Moverare, S. Johansson, M. Hörnqvist, K. Simonsson, S. Sjöström, and B. Sharifimajda. Fatigue crack growth behaviour of Inconel 718 with high temperature hold times. Procedia Engineering, 2(1):1095 - 1104, 2010. Fatigue 2010.

[18] D. Bika, J.A. Pfaendtner, M. Menyhard, and C.J. McMahon Jr. Sulfurinduced dynamic embrittlement in a low-alloy steel. Acta Metallurgica et Materialia, 43(5):1895 - 908, 1995.

[19] J.M. Larsen and T. Nicholas. Load sequence crack growth transients in a superalloy at elevated temperature. Fracture Mechanics: Fourteenth Symposium - Volume II: Testing and Applications, ASTM STP 791, pages II-536-II-552, 1983.

[20] X.B. Liu, L.Z. Ma, K.M. Chang, and E. Barbero. Fatigue crack propagation of Ni-based superalloys. Acta Metallurgica Sinica, 18(1):55-64, 2005.

[21] T. Weerasooriya. Effect of frequency on fatigue crack growth rate of inconel 718 at high temperature. Technical report, Air Force Wright Aeronautical Laboratories Report, AFWAL-TR-87-4038, Wright-Patterson Air Force Base, $\mathrm{OH}, 1987$.

[22] H. Ghonem and D. Zheng. Depth of intergranular oxygen diffusion during environment-dependent fatigue crack growth in alloy 718. Materials Science and Engineering: A, A150(2):151 - 60, 1992.

[23] D. Gustafsson. High temperature fatigue crack propagation behaviour of Inconel 718. PhD thesis, Linköping University, 2013.

[24] R. P. Skelton and J. I. Bucklow. Cyclic oxidation and crack growth during high strain fatigue of low alloy steel. Metal Science, 12(2):64-70, 1978.

[25] J. Gayda, Gabb T.P., and R.V. Miner. Fatigue crack propagation of nickelbase superalloys at $650{ }^{\circ} \mathrm{C}$. In Low Cycle fatigue, ASTM STP 942, pages 293 - 309, 1988.

[26] R. Molins, G. Hochstetter, J.C. Chassaigne, and E. Andrieu. Oxidation effects on the fatigue crack growth behaviour of alloy 718 at high temperature. Acta Materialia, 45(2):663 - 674, 1997. 
[27] U. Krupp. Dynamic embrittlement - time-dependent quasi-brittle intergranular fracture at high temperatures. International Materials Reviews, 50(2):8397, 2005.

[28] D. A. Woodford. Gas phase embrittlement and time dependent cracking of nickel based superalloys. Energy Materials: Materials Science and Engineering for Energy Systems, 1(1):59-79, 2006.

[29] A. Pineau and S.D. Antolovich. High temperature fatigue of nickel-base superalloys - a review with special emphasis on deformation modes and oxidation. Engineering Failure Analysis, 16(8):2668 - 2697, 2009.

[30] A. Saxena. A model for predicting th eenvironmental enhanced fatigue crack growth behavior at high temperature. Thermal and Environmetal Effects in Fatigue-Research Design Interface-PVP-71, ASME, pages 171-184, 1984.

[31] T. Nicholas, T. Weerasooriya, and N.E. Ashbaugh. A model for creep/fatigue interactions in alloy 718. Fracture Mechanics: Sixteenth Symposium, ASTM STP 868, pages 167-180, 1985.

[32] T. Nicholas and T. Weerasooriya. Hold-time effects in elevated temperature fatigue crack propagation. Fracture Mechanics: Seventeenth Volume, ASTM STP 905, pages 155 - 168, 1986.

[33] D. Zheng and H. Ghonem. Oxidation-assisted fatigue crack growth behavior in alloy 718-part II. applications. Fatigue 86 Fracture of Engineering Materials E Structures, 14(7):761-768, 1991.

[34] F. Gallerneau, S. Kruch, and P. Kanouté. A new modelling of crack propagation with fatigue-creep-oxidation interaction under non isothermal loading. In Symposium on Ageing Mechanisms and Control: Part B Monitoring and Management of Gas Turbine Fleets for Extended Life and Reduced Costs, Manchester UK, 8-11 October, 2001.

[35] S. Kruch, P. Prigent, and J.L. Chaboche. A fracture mechanics based fatiguecreep-environment crack growth model for high temperature. International Journal of Pressure Vessels and Piping, 59:141-148, 1994.

[36] J. A. Ruiz-Sabariego and S. Pommier. Oxidation assisted fatigue crack growth under complex non-isothermal loading conditions in a nickel base superalloy. International Journal of Fatigue, 31(11-12):1724 - 1732, 2009. Fatigue Damage of Structural Materials VII.

[37] J.L. Evans and A. Saxena. Elevated temperature crack growth rate model for Ni-base superalloys. Proc. 12th Int. Conf. on Fracture, Ottawa Canada, 2009.

[38] L.G. Zhao, J. Tong, and M.C. Hardy. Prediction of crack growth in a nickelbased superalloy under fatigue-oxidation conditions. Engineering Fracture Mechanics, 77(6):925 - 38, 2010. 
[39] J.L. Evans and A. Saxena. Elevated temperature fatigue crack growth rate model for Ni-base superalloys. International Journal of Fracture, 185(12):209-216, 2014.

[40] A. Saxena and K. Findley. Dwell-time fatigue crack growth in Ni-base superalloys. Technical report, AFRL-ML-TR-2007-4117, Air Force Research Laboratory, Wright-Patterson Air Force Base, OH, 2003.

[41] K.O. Findley, J.L. Evans, and A. Saxena. A critical assessment of fatigue crack nucleation and growth models for $\mathrm{Ni}$ - and $\mathrm{Ni}$, Fe-based superalloys. International Materials Reviews, 56(1):49 - 71, 2011.

[42] J.L. Bouvard, F. Gallerneau, P. Paulmier, and J.L. Chaboche. A phenomenological model to predict the crack growth in single crystal superalloys at high temperature. International Journal of Fatigue, 38:130 - 143, 2012.

[43] K.S. Chan, M.P. Enright, J.P. Moody, B. Hocking, and S.H.K. Fitch. Life prediciton for turbopropulsion systems under dwell fatigue conditions. In Proceedings of ASME Turbo Expo 2012, GT2012-69742, June 11-15, 2012 Copenhagen, Denmark, 2012.

[44] E. Lundström, K. Simonsson, D. Gustafsson, and T. Månsson. A load history dependent model for fatigue crack propagation in Inconel 718 under hold time conditions. accepted for publication in Engineering Fracture Mechanics, 2014.

[45] E. Lundström and K. Simonsson. Evaluation of crack length under hold time conditions in Inconel 718 using a damaged zone concept. submitted, 2014.

[46] B. Sharifimajd. High temperature fatigue crack propagation in Inconel 718. Master's thesis, LIU-IEI-TEK-A-10/00843-SE, 2010.

[47] U. Krupp, W. M Kane, X. Liu, O. Dueber, C. Laird, and C.J McMahon Jr. The effect of grain-boundary-engineering-type processing on oxygen-induced cracking of IN718. Materials Science and Engineering: A, 349(1-2):213 - 217, 2003.

[48] C.J. McMahon Jr. Comments on "Identification of SAGBO-induced damage zone ahead of crack tip to characterize sustained loading crack growth in alloy 783". Scripta Materialia, 54(2):305 - 307, 2006.

[49] L. Viskari, M. Hörnqvist, K.L. Moore, Y. Cao, and K. Stiller. Intergranular crack tip oxidation in a Ni-base superalloy. Acta Materialia, 61(10):3630 3639, 2013.

[50] A. Diboine and A. Pineau. Creep crack initiation and growth in Inconel 718 alloy at $650{ }^{\circ} \mathrm{C}$. Fatigue $\&$ Fracture of Engineering Materials 85 Structures, 10(2):141-151, 1987. 


\section{Part II}

\section{Included papers}





\section{Part II}

\section{Included Papers}

The articles associated with this thesis have been removed for copyright reasons. For more details about these see:

http://urn.kb.se/resolve?urn=urn:nbn:se:liu:diva-104814 